\title{
EDITORIAL
}

\section{Stress failure and high-altitude pulmonary oedema: mechanistic insights from physiology}

\author{
S.R. Hopkins
}

H igh-altitude pulmonary oedema (HAPE) is a potentially fatal altitude illness affecting individuals within 2-4 days of rapid ascent to altitudes above $3,000 \mathrm{~m}$. Although a minority of high-altitude travellers develop HAPE [1], there is some suggestion that many develop subclinical fluid accumulation without overt alveolar flooding [2]. The inciting mechanism of the injury to the lung in HAPE still generates some controversy. However, there is an evergrowing body of evidence that mechanical injury to the pulmonary capillaries induced by high transmural pressures starts a cascade of events that ultimately results in the development of HAPE. This injury, termed "stress failure" described by WEST et al. [3], refers to mechanically induced breaks in the blood-gas barrier, and these have been suggested to be important the pathophysiology of a number of human diseases [4].

In animals, when pulmonary capillaries are subjected to increased transmural pressure, ultrastructural changes consisting of discrete areas of damage to the blood-gas barrier, with rupture of the capillary endothelium, extracellular matrix and the alveolar epithelium, interspersed with large areas of structurally intact blood-gas barrier are observed [5]. Accompanying this is increased permeability of the lung to protein and red blood cells, as measured by increased concentrations in bronchoalveolar lavage fluid [6]. Leukotriene (LT) $\mathrm{B}_{4}$ concentration is also increased in bronchoalveolar lavage fluid [6], perhaps representing cellular activation by exposed basement membrane. Similar findings are observed in some humans following maximal exercise in normoxia [7] where bronchoalveolar lavage fluid contains increased concentrations of red cells, protein and $\mathrm{LTB}_{4}$ thought to result from high pulmonary capillary pressures. In both of these instances, the blood-gas barrier retains sieving function for large molecular weight proteins [6]. However, in established HAPE, permeability to macromolecules is increased [8], and an inflammatory response of the lung to hypoxia has been suggested as an alternate mechanism [9]. In addition, some authors have suggested that HAPE results from altered sodium and water handling by the susceptible lung [10].

Stress failure has been suggested to be important in the development of HAPE largely because of the relationship

Depts of Medicine and Radiology, University of California, San Diego, CA, USA.

CORRESPONDENCE: S.R. Hopkins, Division of Physiology 0623A, University of California, San Diego, 9500 Gilman Dr., La Jolla, CA 92093, USA. E-mail: shopkins@ucsd.edu between high pulmonary vascular pressures and the development of HAPE. A previous history of HAPE is the single greatest predictor of the development of HAPE in future exposures and HAPE-susceptible individuals generally have augmented hypoxic pulmonary vasoconstriction and increased pulmonary vascular pressures when exposed to hypoxia [1115] and exercise [16]. In addition, drugs such as sidenafil, nifedipine, tadaphil and dexamethasone reduce pulmonary vascular pressures and reduce the severity of HAPE $[17,18]$ or prevent the development when administered prophylactically [19]. Since the primary site of hypoxic pulmonary vasoconstriction is thought to be pre-capillary, hypoxic pulmonary vasoconstriction is hypothesised to be uneven [20, 21], subjecting capillaries in nonconstricted lung regions to higher pressures and structural injury. This uneven perfusion is supported by studies in animals [22] as well as imaging studies in HAPE-susceptible humans [23, 24]. Also, in support of the initial leak in HAPE as non-inflammatory and related to increased hydrostatic pressure are studies in HAPE-susceptible subjects and control subjects with a history of repeated exposure to high altitude without symptoms [25]. At 4,559 m, HAPE-susceptible subjects had greater pulmonary capillary pressures than controls and this was greater in individuals who were clinically ill with HAPE. Bronchoalveolar lavage fluid obtained shortly after ascent showed increased red blood cell and protein concentrations in HAPE-susceptible subjects compared to control subjects, with a greater increase in those HAPE-susceptible subjects that were clinically ill with HAPE. However, there were no elevations in inflammatory mediators or cells in any of these subjects indicating that the development of the leak precedes the development of inflammation in these subjects. All of this evidence, however convincing, is not direct proof of the presence of capillary stress failure in HAPE.

In a carefully controlled study published in this issue, BAI et al. [26], working with a rat model, link for the first time direct histological evidence of pulmonary capillary stress failure and the development of a HAPE-like illness. Although it has been previously shown that rats, rapidly decompressed to extremely low barometric pressures, developed evidence of stress failure [27] the link to HAPE had not been fully established. The strength of the work of BAI et al. [26], is the comprehensive and well controlled nature of the study design: animals who were subjected to physiologically relevant levels of hypobaric hypoxia $(420 \mathrm{mmHg}$, altitude $\sim 4,700 \mathrm{~m}$ ) developed an increase in lung wet-to-dry ratio, and bronchoalveolar lavage fluid total protein, albumin and red blood cell concentrations, indicating that these animals had increased lung water and 
bronchoalveolar lavage findings similar to human HAPE. These changes were greater in animals that were subjected to very strenuous exercise while hypoxic and were not seen in normoxic resting or normoxic exercising control animals. Post mortem histological evaluation of the lung showed that both groups of hypoxic animals had an increase in the thickness of the alveolar septum on light microscopy compared with the normoxic animals. Haemorrhagic alveolar oedema was present in the hypoxic exercising animals but not the other three groups, although a small number of red blood cells were found in both the resting hypoxic and exercising normoxic groups. On electron microscopy, gross changes were observed in the blood-gas barrier of the hypoxic exercising animals consisting of regions of disruption of the alveolar epithelium and capillary endothelium as classically described by WEST. Importantly, changes of this magnitude were not observed in any of the other groups of animals. In addition, the number of breaks observed across the all of the animal groups showed highly significant relationships with the red cell, and protein concentrations as well as the wet-to-dry ratio of the lung and the alveolar arterial difference providing a link between the severity of the injury to the blood gas barrier and the clinical manifestations of illness.

Although stress failure is linked to the development of florid pulmonary oedema at altitude, there is good evidence that during intense sea level exercise both humans [7] and animals develop stress failure of pulmonary capillaries and in some species, such as horses, this is a regular occurrence [28]. However alveolar flooding after sea level exercise has been rarely reported in humans and is limited to situations where the exercise task has been truly extraordinary [29] or during water immersion [30]. Therefore, stress failure is not in itself enough to incite pulmonary oedema, leaving many questions about HAPE unanswered. So what are the next steps in the pathogenesis of HAPE after the initial damage to the blood-gas barrier? It has been shown that the breaks in the pulmonary blood-gas barrier close very quickly after the pressure is reduced and, given the rapid improvements with descent, oxygen and pulmonary vasodilators, an ongoing elevation of pulmonary vascular pressures is clearly important in HAPE. In addition, a brisk inflammatory response likely accentuates an underlying leak, but this has not been completely elucidated. What are the roles of previous viral infection and altered alveolar fluid clearance in the genesis of HAPE? There are many facets of this interesting problem yet to be elucidated. It should be noted that the exercising rat model may be helpful, but in general rats have proven to be quite resistant to the development of HAPE, requiring either very severe hypoxaemia, endotoxin priming or, as in the study of BAI et al. [26], extremely high levels of sustained exercise.

Why should we care about understanding the mechanism of HAPE, which affects so few individuals and is easily preventable simply by limiting altitude exposure or by prophylaxis with dexamethasone or pulmonary vasodilators? HAPE research may offer insights into several types of pulmonary oedema occurring at low elevations such as neurogenic pulmonary oedema and reperfusion pulmonary oedema. In addition, understanding the relationships between lung mechanical stress injury and oedema may, if not provide insights into the mechanism of acute lung injury and acute respiratory distress syndrome, at least allow better selection of therapeutic strategies that minimize the risk of additional lung injury [31].

In an era of reductionist science where organ-level physiology is commonly viewed as lacking in mechanistic insights, research investigating the mechanisms of HAPE has largely been conducted in whole animal models and humans. From the early work of WEST and co-workers, first comprehensively identifying the vulnerability of the lung to mechanical stress failure and predicting the importance of stress failure in a variety of human illness [4, 32-34], to later work in human volunteers providing the first evidence for stress failure in HAPE [25], the work of BAI et al. [26], and that of a great many other contributors, highlights the importance of applying the understanding of normal physiological responses in humans and whole animal models to the study of disease. To quote the French physiologist Claude Bernard, "Effects vary with the conditions which bring them to pass, but laws do not vary. Physiological and pathological states are ruled by the same forces; they differ only because of the special conditions under which the vital laws manifest themselves" [35].

\section{STATEMENT OF INTEREST}

None declared.

\section{REFERENCES}

1 Schoene R, Swenson E, Hultgren H. High altitude pulmonary edema. In: Hornbein $\mathrm{T}$, Schoene R, eds. High Altitude: An exploration of human adaptation. New York, Marcel Dekker Inc., 2001; pp. 777-814.

2 Cremona G, Asnaghi R, Baderna P, et al. Pulmonary extravascular fluid accumulation in recreational climbers: a prospective study. Lancet 2002; 359: 303-309.

3 West JB, Tsukimoto K, Mathieu-Costello O, et al. Stress failure in pulmonary capillaries. J Appl Physiol 1991; 70: 1731-1742.

4 West JB, Mathieu-Costello O. Stress failure of pulmonary capillaries: role in lung and heart disease. Lancet 1992; 340: 762-767.

5 Tsukimoto K, Mathieu-Costello O, Prediletto R, et al. Ultrastructural appearances of pulmonary capillaries at high transmural pressures. J Appl Physiol 1991; 71: 573-582.

6 Tsukimoto K, Yoshimura N, Ichioka M, et al. Protein, cell, and LTB4 concentrations of lung edema fluid produced by high capillary pressures in rabbit. J Appl Physiol 1994; 76: 321-327.

7 Hopkins SR, Schoene RB, Henderson WR, et al. Intense exercise impairs the integrity of the pulmonary blood-gas barrier in elite athletes. Am J Respir Crit Care Med 1997; 155: 1090-1094.

8 Schoene RB, Hackett PH, Henderson WR, et al. High-altitude pulmonary edema. Characteristics of lung lavage fluid. JAMA 1986; 256: 63-69.

9 Kubo K, Hanaoka M, Hayano T, et al. Inflammatory cytokines in BAL fluid and pulmonary hemodynamics in high-altitude pulmonary edema. Respir Physiol 1998; 111: 301-310.

10 Mairbaurl H, Schwobel F, Hoschele S, et al. Altered ion transporter expression in bronchial epithelium in mountaineers with highaltitude pulmonary edema. J Appl Physiol 2003; 95: 1843-1850.

11 Hultgren HN, Grover RF, Hartley LH. Abnormal circulatory responses to high altitude in subjects with a previous history of high-altitude pulmonary edema. Circulation 1971; 44: 759-770.

12 Kawashima A, Kubo K, Kobayashi T, et al. Hemodynamic responses to acute hypoxia, hypobaria, and exercise in subjects susceptible to high-altitude pulmonary edema. J Appl Physiol 1989; 67: 1982-1989. 
13 Viswanathan R, Jain SK, Subramanian S, et al. Pulmonary edema of high altitude. II. Clinical, aerohemodynamic, and biochemical studies in a group with history of pulmonary edema of high altitude. Am Rev Respir Dis 1969; 100: 334-341.

14 Yagi $\mathrm{H}$, Yamada $\mathrm{H}$, Kobayashi $\mathrm{T}$, et al. Doppler assessment of pulmonary hypertension induced by hypoxic breathing in subjects susceptible to high altitude pulmonary edema. Am Rev Respir Dis 1990; 142: 796-801.

15 Grunig E, Mereles D, Hildebrandt W, et al. Stress Doppler echocardiography for identification of susceptibility to high altitude pulmonary edema. J Am Coll Cardiol 2000; 35: 980-987.

16 Eldridge MW, Podolsky A, Richardson RS, et al. Pulmonary hemodynamic response to exercise in subjects with prior highaltitude pulmonary edema. J Appl Physiol 1996; 81: 911-921.

17 Oelz O, Maggiorini M, Ritter M, et al. Nifedipine for high altitude pulmonary oedema. Lancet 1989; 2: 1241-1244.

18 Scherrer U, Vollenweider L, Delabays A, et al. Inhaled nitric oxide for high-altitude pulmonary edema. N Engl J Med 1996; 334: 624-629.

19 Maggiorini M, Brunner-La Rocca HP, Peth S, et al. Both tadalafil and dexamethasone may reduce the incidence of high-altitude pulmonary edema: a randomized trial. Ann Intern Med 2006; 145: 497-506.

20 Visscher MB. Studies on embolization of lung vessels. Med Thorac 1962; 19: 334-340.

21 Hultgren HN. Pulmonary hypertension and pulmonary edema. In: Loeppky JA, Riedesel ML, eds. Oxygen Transport to Human Tissue. New York, Elsevier/North Holland, 1982; pp. 243254.

22 Hlastala MP, Lamm WJ, Karp A, et al. Spatial distribution of hypoxic pulmonary vasoconstriction in the supine pig. J Appl Physiol 2004; 96: 1589-1599.

23 Dehnert C, Risse F, Ley S, et al. Magnetic resonance imaging of uneven pulmonary perfusion in hypoxia in humans. Am J Respir Crit Care Med 2006; 174: 1132-1138.
24 Hopkins SR, Garg J, Bolar DS, et al. Pulmonary blood flow heterogeneity during hypoxia and high-altitude pulmonary edema. Am J Respir Crit Care Med 2005; 171: 83-87.

25 Swenson ER, Maggiorini M, Mongovin S, et al. Pathogenesis of high-altitude pulmonary edema: inflammation is not an etiologic factor. JAMA 2002; 287: 2228-2235.

26 Bai C, She J, Goolaerts A, et al. Stress failure plays a major role in development of high-altitude pulmonary oedema in rats. Eur Respir J 2010; 35: 584-591.

27 West JB, Colice GL, Lee YJ, et al. Pathogenesis of high-altitude pulmonary oedema: direct evidence of stress failure of pulmonary capillaries. Eur Respir J 1995; 8: 523-529.

28 Whitwell KE, Greet TR. Collection and evaluation of tracheobronchial washes in the horse. Equine Vet J 1984; 16: 499-508.

29 McKechnie JK, Leary WP, Noakes TD, et al. Acute pulmonary oedema in two athletes during a 90-km running race. S Afr Med J 1979; 56: 261-265.

30 Weiler RD, Shupak A, Goldenberg I, et al. Pulmonary oedema and haemoptysis induced by strenuous swimming. BMJ 1995; 311: 361-362.

31 Amato MBP, Barbas CSV, Medeiros DM, et al. Effect of a protective-ventilation strategy on mortality in the acute respiratory distress syndrome. N Engl J Med 1998; 338: 347-354.

$32 \mathrm{Fu} \mathrm{Z,} \mathrm{Costello} \mathrm{ML,} \mathrm{Tsukimoto} \mathrm{K,} \mathrm{et} \mathrm{al.} \mathrm{High} \mathrm{lung} \mathrm{volume} \mathrm{increases}$ stress failure in pulmonary capillaries. J Appl Physiol 1992; 73 123-133.

33 West JB, Colice GL, Lee YJ, et al. Pathogenesis of high-altitude pulmonary oedema: direct evidence of stress failure of pulmonary capillaries. Eur Respir J 1995; 8: 523-529.

34 West JB, Mathieu-Costello O. Stress failure in pulmonary capillaries: a mechanism for high altitude pulmonary edema. In: Sutton JR, Coates G, Houston CS, eds. Hypoxia and Mountain Medicine. Burlington, Queen City Printers Inc., 1992; pp. 229-240.

35 Bernard, C, An Introduction to the Study of Experimental Medicine (1865). New York, Dover, 1927. 